\title{
Imagem e performance: estudos sobre coletivos de jovens urbanos e música popular massiva
}

\author{
MARCUS RAMUSYO DE ALMEIDA BRASIL
}

Resumo

O artigo propõe uma articulação entre aspectos políticos, identitários e performáticos dos gênero/estilos musicais ligados a jovens urbanos de zonas pobres de grandes cidades. Elenquei para a pesquisa o reggae, em São Luís, e o tecnobrega, em Belém, como expressões artísticas e fenômenos culturais emblemáticos para identificar os contornos da cultura massiva contemporânea. Interessa ao trabalho a historização, a apresentação da metodologia e a produção de uma etnografia visual, além dos traços discursivos aplicados pelas mídias e instituições na (des)legitimação das políticas de representação social dos grupos objeto(s) da pesquisa.

Palavras-chave:

Tecnobrega, reggae, performance. 


\title{
"Image and performance: studies about teenage urban collectives and massive popular music"
}

\author{
MARCUS RAMUSYO DE ALMEIDA BRASIL
}

\begin{abstract}
The study seeks to investigate the articulation between identity traits, politics and performance in midst musical styles linked to teenage urban collectives living in the outskirts of two major cities in Brazil. The study takes as objects the musical genders of reggae in São Luis and tecnobrega in Belem as artistic expressions and cultural phenomena. It matters to the text the historicity of the object, presentation of the methodological proposal and production of a visual ethnography of these phenomena. It is also important the discursive traces produced by political institutions and mass media, trying to legitimize or delegitimize the social representation of the social groups object to this study.
\end{abstract}

Keywords: Tecnobrega, reggae, performance. 
Um método científico se distingue pelo fato de, ao encontrar novos objetos, desenvolver novos métodos - exatamente como a forma na arte que, ao conduzir a novos conteúdos, desenvolve novas formas. Apenas exteriormente uma obra de arte tem uma e somente uma forma, e um tratado científico tem um e somente um método.

BENJAMIN, 2009, p. 515, [N 9, 2]

Tratar o passado, ou melhor: tratar o ocorrido, não como se fez até agora, segundo o método histórico, mas segundo o método político. Transformar as categorias políticas em teóricas, eis a tarefa... A perscrutação dialética e a presentificação de conexões do passado são a prova de verdade da ação presente.

IDEM, p. 939, [cf. K 2, 3]

\section{Introdução}

O presente texto propõe uma prospecção investigativa que propicie uma articulação entre aspectos políticos, identitários e performáticos dos gêneros/estilos musicais ligados aos coletivos de jovens urbanos de zonas pobres das grandes cidades do Brasil. Elenquei como objeto(s) de pesquisa o reggae, em São Luís-MA, e o tecnobrega, em Belém-PA, como expressões artísticas e fenômenos culturais emblemáticos para identificar os contornos da cultura massiva contemporânea. Interessam à pesquisa as relações entre a formação dos discursos hegemônicos e contra-hegemônicos que são construídos pelos campos midiáticos, comunitários, sociais e pelas instituições, na legitimação e na deslegitimação das políticas de representação dos grupos objeto(s) desta pesquisa.

Nesseartigo, o esforçoéapresentar as balizas fundamentais que norteiam o referencial histórico e o método de campo do 
projeto de pesquisa pós-doutoral: "Reggae, funk e tecnobrega: política, identidade e performance nos coletivos de jovens urbanos da contemporaneidade". Do ponto de vista do método, lanço mão da antropologia visual, e gero, a partir de duas experiências de campo, uma numa festa de tecnobrega da aparelhagem Badalasom, em Belém-PA, e outra em um baile de reggae da radiola ${ }^{1}$ Itamaraty, em São Luís-MA, protocolos de imagens e observações diretas, feitas com equipes de pesquisa que possibilitaram enxergar as performances dos coletivos de jovens como gestos poéticos ${ }^{2}$ dos corpos dançantes, cheios de significantes e traços de representação inscritos enquanto identidade. Esse movimento oportuniza uma relação dialógica intensa e também performática da equipe, na medida em que direciona suas lentes ao objetos/sujeitos da pesquisa.

\section{Os gêneros/estilos do tecnobrega e do reggae}

Entre os gêneros/estilos tecnobrega no Pará e reggae no Maranhão, identifica-se uma raiz comum em sua matriz musical, que é a influência da música afrocaribenha. Mesmo porque o litoral norte do Brasil é considerado como mar do Caribe. Os fluxos migratórios e sonoros construíram heranças e transformações musicais que, hoje em dia, promovem, através das manifestações que geram, grandes mercados consumidores, com forte influência nas formações das coletividades através de traços em comum de gosto e comportamento grupal, afetando a formação das novas subjetividades periféricas, que são alçadas a uma grande visibilidade pela força que possuem.

O tecnobrega surge no Pará, mais precisamente na Belém de 1990, como um gênero derivado da música brega que, ao se misturar com o calypso caribenho, obteve uma aceleração do beat e um arranjo mais eletrônico, como podemos observar na passagem a seguir:

Com a influência do ritmo caribenho, aceleração das batidas e a introdução de guitarras, surge o bregacalypso, na voz não apenas de cantores antigos, mas também de novos artistas, atraindo um público mais amplo e diferente. O estilo propagou-se pelas regiões Norte e Nordeste do Brasil, e chegou até mesmo a Caiena, capital da vizinha Guiana Francesa (Lemos e Castro, 2008, pp. 27-28).

A versão mais eletrônica e rápida do bregacalypso foi a que se chamou, entre 2001 e 2003 , de tecnobrega, que “... 
nasceu da fusão da música eletrônica com o brega tradicional" (IDEM, p. 28). Foi fomentado à margem das grandes gravadoras e dos grandes sistemas de comunicação e construiu todo um aparato tecnológico para as festas a partir da promoção e da rentabilidade das aparelhagens de tecnobrega e das vendas de CDs de fabricação e distribuição rápida em shows e espetáculos. A divulgação das festas é feita a partir de estratégias e meios de comunicação próprios. Os produtores dos programas de rádio e televisão das aparelhagens compram espaço de veiculação nos grandes conglomerados de comunicação de massa, ao passo em que também divulgam seus eventos em rádios comunitárias e em carros de som pelos bairros populares. Apesar dessa característica vicinal, as festas tem um caráter extremamente massivo, tendo em vista que mobilizam milhares de pessoas a cada apresentação das aparelhagens de tecnobrega pela grande Belém e interiores do estado do Pará.

As marcas fundamentais que caracterizam o tecnobrega são seu ritmo muito rápido, de acento caribenho, e sua textura sonora eletrônica, com especial preferência pelos timbres de que agitam o público presente e se identificam com ele.

O reggae surge na Jamaica, em meados dos anos 1960, sonoramente oriundo de um entrecruzamento entre o mentho, ritmo rural jamaicano, e o R\&B americano, que lá chegou pelas rádios locais. Liricamente, está ligado às concepções político-ideológicas da religião rastafári³ ${ }^{3}$ As condições sociais e econômicas dos grupos sociais afrodescendentes da ilha caribenha propiciaram o surgimento de um sistema simbólico constituído nas relações de transcendência e interrelação entre as dimensões política, religiosa e artística, que se traduzia na construção de uma identidade política e cultural para os negros e pobres, considerados "outsiders"4. Estes eram compostos, principalmente, pelos "rastafarianos", que eram pessoas de espiritualidade, tocavam os tambores tribais, consumiam "ganja" e viviam na zona rural da Jamaica (HEBDIGE, 1987). Em sua maioria, eram líderes espirituais que recusavam contato com a Babilônia. A Babilônia metaforiza, no posicionamento ideológico dos rastafáris, um mundo de crime, de injustiça, de corrupção e de violência, no qual só se produz guerra e dor. Na Jamaica, a Babilônia estaria incorporada às figuras da Igreja Católica, do governo e da polícia. Os outros "outsiders" da Jamaica estavam localizados nas grandes concentrações populacionais urbanas de Kingston e, sem dúvida, situavam-se mais 
intensamente nos bairros Trench Town e Chanty Town, os bairros de lata. Constituída basicamente de afrodescendentes, a maioria era oriunda do êxodo rural que, em busca de melhores condições de sobrevivência, migrou para as favelas da capital, onde nasceu e se desenvolveu o reggae tal qual se concebe hoje.

A cidade de São Luís do Maranhão, na atualidade, é reconhecida nacionalmente como a "Ilha do Reggae", a "Jamaica brasileira”. Para alcançar esse título, a capital maranhense e outras cidades do estado passaram por vários processos de socialização, identificação e apropriação desse gênero musical ao longo de mais de trinta anos, tendo em vista que o reggae aportou no Maranhão em meados dos anos 1970. Noutra pesquisa desenvolvida (BRASIL, 2005), abordei a chegada do reggae ao solo maranhense via grande fluxo migratório entre Maranhão e Pará, devido à construção da estrada de ferro de Carajás, da Companhia Vale do Rio Doce - CVRD. Na capital paraense, nessa época, já se tocava muita música caribenha e já existiam os "Sound Systems", grandes aparelhagens de som, ideia importada da Jamaica e de outros países da América Central. Outras fontes revelam que discos de vinil eram dados às prostitutas e vendidos ou trocados por outros produtos com os trabalhadores do porto do Itaqui pelos marinheiros que ali aportavam, dentre eles, alguns vinis de reggae e outras músicas caribenhas, que logo se tornaram sucesso; e a terceira versão é a de que a música também chegou via rádio de ondas baixas e rádio amadores do caribe.

Percebe-se, portanto, que a introdução do reggae no Maranhão, mais especificamente na Baixada Maranhense e em São Luís, dá-se de forma eminentemente vicinal, operacionalizada por estratos sociais menos abastados da sociedade. A partir da disseminação do reggae como estilo musical internacional preferido nas áreas menos abastadas de São Luís, é constante a presença das festas de reggae dentro das páginas policiais dos principais jornais da cidade, estes sempre ligados aos grupos hegemônicos de poder.

Ao longo dos anos, o reggae sofre um processo de apropriação pelos grupos sociais pobres da capital, em sua maioria de afrodescendentes. A primeira ressignificação pelos maranhenses com o reggae jamaicano aconteceu com o nome das músicas. Como a maioria dos adeptos do novo gênero não entendia a língua inglesa, uma forma particular de identificar a música foi a criação dos melôs. Os melôs são "aportuguesamentos" dos nomes das músicas a partir da proximidade fôni- 
ca de um trecho em inglês ou com algum elemento do mundo fenomenológico local, ou mesmo em homenagem a alguém. Por exemplo, a música White Witch, da banda Andréa True Connection, tem o título "Melô do Caranguejo". O refrão dessa música diz "What's gonna get you" (o que te chamará atenção), e o regueiro maranhense "adapta", livremente, para "olha o caranguejo", pela proximidade sonora que ele percebe. Então a música é (re)batizada (ARAÚJO, 2004). Os melôs também podem ser em homenagem a pessoas que frequentam as festas, como o "Melô de Valéria" e o "Melô de Poliana". As significações são livres. Certa vez, tocou-se uma música nova em um baile de reggae e nesse dia teria chovido muito. Como o DJ não havia nomeado a canção, ela foi batizada de "Melô da Chuva". Os melôs são verdadeiras reconstruções semânticas que estreitam os universos do reggae da Jamaica com o povo maranhense (BRASIL, 2011).

Do ponto de vista mercadológico, o advento do melô servia (no início do reggae no Maranhão - décadas de 1970 e 1980) para omitir o nome verdadeiro da música em inglês e, assim, dificultar que outro colecionador ou DJ obtivesse determinada música que só uma radiola tinha. Isso gerava um sistema de exclusividade das canções. Cada radiola, ou DJ, tinha seus melôs exclusivos, e o público ia para ouvir essas músicas, pois sabiam que a única oportunidade seria na festa de uma radiola ou de um disquejóquei específicos (SILVA, 1992).

Também havia e ainda há o hábito de carimbar as músicas. Carimbar é jogar uma vinheta da radiola ou do DJ durante a execução do som, para que, se estiver sendo gravada em fita $\mathrm{K}_{7}$, pelo rádio, ou em $\mathrm{MD}$ ou $\mathrm{CD}$, via aparelhagem de som, a música exclusiva não acabe caindo nas mãos de algum concorrente. Essa estratégia garantia o valor diferencial de cada grupo de radiola e dos DJs, e realizava a divulgação dos grupos, além de ser um fator de marcação, através da repetição do nome da radiola, do disquejóquei, tornando-os muito conhecidos nas festas e em suas comunidades de realização.

A aproximação e a afirmação do reggae como gênero musical naturalizado ao universo da cultura popular maranhense aconteceram em um processo de tessitura realizada a partir da realidade caribenha do litoral do Maranhão, assim como na Jamaica. A vinda de negros das mesmas etnias aos portos da Jamaica e à capitania do Maranhão gera uma rede de relações identitárias que se perderam na violência física e simbólica da escravidão, e foi reconstruída de forma dissonante, transversal e local nas travessias da comunicação opor- 
tunizadas pela intensificação dos fluxos informacionais e dos mercados transnacionais que surgiram no último quartel do século XX (BRASIL, 2011).

\section{Por uma questão de método}

A palavra "método", no sentido etimológico, do grego "méthodos", significa "caminho", "via", no que tange às questões da investigação científica (CUNHA, 2007, p. 517). O caminho que escolhi para trilhar esta pesquisa tem uma influência muito grande das categorias de análise que elegi para estudar as relações entre identidade e política nas culturas jovens periféricas contemporâneas ligadas à música popular massiva. Pergunto me sobre onde estão localizados a resistência e o contra-hegemônico hoje. Creio que muitas das respostas se encontram nas políticas do corpo. Porque, no limite, o corpo é a última instância da resistência, pois nele se dão as violações e as assunções, sobretudo sobre e nos corpos dos menos favorecidos.

Para entender como o corpo responde, negocia, impõe se, adapta-se, desvia-se e constrói seu próprio discurso sobre a subjetividade do ser, que reverbera coletivamente, decidi, como estratégia de pesquisa de campo, realizar registros videográficos e fotográficos que estabelecessem um diálogo com as pessoas e os corpos dessas pessoas que estão no baile de tecnobrega e na festa de reggae. Buscar, através dos traços da dança, das interações com o grupo social, da relação com a moda, com o gestual, com a oralidade, com o sentido da vibração sonora e imagética, identificar os campos de significação possíveis de serem observados e analisados. Compreender como o corpo se instaura como elemento da cultura, como, em primeira e em última instância, o cultural se dá e vive fenomenicamente através de um corpo que sente, que transborda, que vibra, que pulsa.

Por essa razão, pela necessidade de desvelar as estratégias do corpo, fui levado a elencar, como um dos eixos centrais de minha proposta de investigação, a performance como chave conceitual para tentar decifrar aquilo que nos diz o corpo em ação. A perspectiva de Paul Zumthor sobre performance é a que adoto como a mais próxima do entendimento desse pensamento:

Estou particularmente convencido de que a idéia de performance deveria ser amplamente estendida... Relaciono-a ao momento decisivo em que todos os elementos cristalizam em 
uma e para uma percepção sensorial - um engajamento do corpo. (2007, p. 18)

Esse "engajamento do corpo" de que trata Zumthor é que me interessa como substrato para observar os coletivos de jovens urbanos, que se identificam com as músicas populares do tecnobrega e do reggae, e constroem suas identidades a partir desses gêneros/estilos musicais de caráter local/global. Gêneros/estilos musicais mestiços em suas essências e genuínos em suas práticas, com suas características próprias e específicas, mas também com similitudes observáveis, sujeitas a possíveis aproximações.

O que me parece revelador no corpo é sua capacidade de significar, através do seu movimento, aquilo que o sujeito está sentindo e expressando como forma, como posicionamento, no sentido propriamente espacial do termo. Uma forma-força tal como coloca Zumthor, ressaltando que "... a forma não é regida pela regra, ela é a regra. Uma regra a todo instante recriada, existindo apenas na paixão do homem.... (IDEM, p. 29). Nesse sentido, a performance dos corpos dos adeptos que frequentam os bailes de tecnobrega e reggae falam muito sobre o posicionamento e sobre o ethos dos grupos sociais que ali estão para se divertir, para se verem representados e para representarem. A festa, nesse sentido, constitui-se como o espaço de representação do sujeito e sua performance corporal na festa, que se dá através da moda, da fala, do gesto, da dança, da forma de se portar etc., realiza-se como um saber-ser, termo utilizado por Zumthor para caracterizar as "... coordenadas espaço-temporais e fisiopsíquicas concretas, uma ordem de valores encarnada em um corpo" (IBIDEM, p. 31). A intenção desse esforço reflexivo é entender como se constroem os contornos identitários dos coletivos de jovens urbanos, que são constituídos por esses sujeitos que aqui entendo sempre como um indivíduo-coletivo, ou seja, um ser advindo da fricção constante entre processos de interação social e de subjetivação.

Nos espaços de realização das festas de tecnobrega e de reggae em Belém - PA e São Luís - MA, respectivamente, percebe-se uma presença forte do ideário jovem de diversão e entretenimento. Tomo aqui a ideia de juventude não no sentido etário, mas como um termo que desperta e impõe uma forma de estar e uma forma de ser em determinado contexto, nesse caso, o contexto da festa. Dessa forma, o termo juventude evoca mais um estilo de vida e uma categoria de 
consumo do que uma classificação etária propriamente dita, apesar de não se poder olvidar das dimensões geracional e biológica da juventude. Para entender essa noção de juventude, é necessário que se visualize e se articule como, e, em que medida, estabelecem-se os significantes corporais que constituem os grupos sociais que frequentam as festas de tecnobrega e reggae.

Para tanto, optei como método de campo a produção de imagem videográfica e fotográfica em festas de tecnobrega e reggae, propondo, dessa forma, um encontro, um diálogo aberto entre a minha presença e de minha equipe dentro das festas, a fim de observar como os corpos se comportam frente às lentes das câmeras fotográficas e às das filmadoras. Utilizo como alicerce teórico para os procedimentos de campo o pensamento de Novaes, que aponta que:

Arquivos de imagens e imagens contemporâneas coletadas em pesquisa de campo podem e devem ser utilizados como fontes que conectam os dados à tradição oral e à memória dos grupos estudados. Assim, o uso da imagem acrescenta novas dimensões à interpretação da história cultural, permitindo aprofundar a compreensão do universo simbólico, que se exprime em sistemas de atitudes por meios dos quais grupos sociais se definem, constroem identidades e apreendem mentalidades (2005, p. 110).

Penso que a produção de imagens ajudará muito a entender como a forma de dançar dos coletivos de jovens urbanos, que, em sua maioria, são mestiços de origem negra e indígena, por exemplo, logram êxito na territorialização dos gêneros/estilos que são dançados, naturalizando-os e transformando-os em objetos culturais que identificam determinada cidade, tal como o reggae em São Luís - MA e o tecnobrega em Belém - PA. Dessa forma, a visualidade sobre a dança acrescenta variadas possibilidades de análise, podendo-se voltar inúmeras e diferentes vezes sobre o movimento captado pelas lentes de pesquisa. Assim, a dança torna-se a dimensão espacial da música que está sendo tocada, como sugere Sodré, em seu livro Samba, o dono do corpo, corroborando com uma mirada imagética (fotográfica e audiovisual) sobre os fenômenos musicais.

Na cultura negra (...) a interdependência da música com a dança afeta as estruturas formais de uma e de outra, de tal maneira que a forma musical pode ser elaborada em função 
de determinados movimentos de dança, assim como a dança pode ser percebida como uma dimensão visual da forma musical (1998, p. 22).

A intenção é, a partir da forma, do gesto, das "marcas" deixadas pelo corpo, extrair conteúdos significativos sobre de que modo as formas musicais do tecnobrega e do reggae afetam as subjetividades dos grupos sociais que se identificam com os gêneros/estilos e participam das festas dessas músicas, que se realizam na lógica das aparelhagens de sound systems, sob o comando do DJ como elo de mediação entre aparelhagem e público, e com a materialidade vibracional do som da música como elemento fundamental desses fenômenos culturais. Interessa saber, também, como ocorrem os trânsitos de retroalimentação entre produção, produto e recepção, ou seja, em que medida as reações do público influenciam as intervenções orais do DJ, a escolha do set list de músicas a serem tocadas na festa, a dinâmica das mesmas, e, inclusive, questões relacionadas à forma musical das canções no tocante à velocidade, ao timbre e à textura do som.

\section{Mídia, identidade e performance: uma articulação metodológica}

O objetivo da presente proposta investigativa é entender os discursos hegemônicos e contra-hegemônicos sobre o tecnobrega e o reggae que são produzidos fora e dentro das zonas de exclusão. Perceber como há certo rechaço das classes mais abastadas das cidades de Belém - PA e São Luís - MA, classificando como perigosas as festas da cultura popular urbana. Assim como uma distorção da mídia, predisposta a criminalizar os gêneros/estilos do tecnobrega e do reggae, e seus respectivos públicos, através de impregnação de violências simbólicas, associando as festas ao acontecimento de crimes. Nas experiências de campo que tive ao longo de 10 anos, frequentando e pesquisando música popular urbana, nunca me senti inseguro, inclusive, sempre percebi que o esquema de segurança desses eventos é bem forte.

Na ocasião do Fórum Social Mundial de 2009, que ocorreu em Belém - PA, a governadora à época, Ana Júlia do PT (Partido dos Trabalhadores), proibiu a realização dos bailes de tecnobrega na capital paraense durante o evento, porque, segunda ela: "As aparelhagens são perigosas" [Sic]. Em minha tese de doutorado, intitulada "O reggae no Maranhão: música, mí- 
dia e poder" (2011), analisei os periódicos da cidade de São Luís - MA, de 1976 a 2004. Busquei em que contexto aparecia a palavra reggae dentro das notícias da cidade. Constatei que, de 1976 a 1999, o termo reggae apareceu eminentemente nos cadernos policiais. Manchetes como: "Crime brutal após noitada de reggae" [Jornal Pequeno, 10/02/1993]; ou então: "Jovem abatido à bala no reggae da Deodoro" [Jornal Pequeno, 24/04/1993] são comuns nesse período. Também se percebe, em uma determinada manchete, a tentativa de contrapor o reggae, estrangeiro, ao bumba-meu-boi, manifestação popular tradicional maranhense: "Reggae bota Boi da Maioba para fugir de seu terreiro" [Jornal Pequeno, 11/o6/1994]. O reggae só migrou às páginas de cultura dos jornais a partir dos anos 2000.

Un análisis cultural democrático como el que postulamos debe, entonces y en primer lugar, desmontar la simulación de la hiperrepresentación; y debe proponer, política y eficazmente, el derecho imprescriptible al simbolismo de todos los grupos y classes sociales. Es decir, debe desconstruir ese poliglotismo falaz, la falacia de una polifonia inverificable que se vuelve, a duras penas, cacofonía: un concierto de ruidos donde lo hegemónico permanece duramente inalterado (ALABARCES, 2008, p. 26).

Partindo dessa mirada colocada por Alabarces na introdução do livro Resistencias e mediaciones: estúdios sobre cultura popular, vejo como necessário aos estudos sobre a música popular apreender as condições sociais propiciadas para a assunção das identidades advindas dos gêneros/estilos musicais periféricos de caráter urbano. E mais, abstrair dos códigos significantes inscritos nos estilos de vida, na linguagem corporal etc., o posicionamento político, no sentido de uma política-vida, que são operacionalizados pelos gêneros/ estilos aqui estudados.

Esse esforço oportuniza entender e analisar aquilo que Williams propôs na noção de "estruturas de sentimento", na qual ele trabalha a relação entre o pensamento e os sentidos do mundo cultural através do corpo/mente, a partir de elementos de afetividade oportunizados pela prática cultural e pelo sentimento de estar, ser, participar, pôr-se em relação, que se constitui, no limite, como um ato político.

Estamos hablando de los elementos característicos de impulso, restricción y tono; elementos especificamente afectivos de 
la consciencia y las relaciones, y no sentimiento contra pensamiento, sino pensamiento tal como es sentido y sentimiento tal como es pensado; una consciencia práctica de tipo presente, dentro de una continuidad vivida e interrelacionada. En consecuencia, estamos definiendo estos elementos como una "estructura”: como un grupo con relaciones internas específicas, entrelazadas y a la vez en tensión (WILLIAMS, 1997, p. 155).

Tal movimento reflexivo possibilita à análise social dos grupos sociais juvenis urbanos de áreas de exclusão uma perspectiva mais ampla, na medida em que, através da performance dos coletivos de jovens, observamos as construções identitárias que conformam o universo simbólico dos mesmos.

Importante é, após captar metodicamente as performances e observar a construção das identidades, promover uma análise do aspecto político referente às políticas de representação social desses grupos. Saber como se constituem os discursos opositivos deles ao discurso hegemônico, assim como também enxergar onde estão as negociações realizadas, para entender como tais identidades periféricas se colocam, ainda e sempre, como uma questão de classe. Portanto, trata-se de uma questão política, no sentido da disputa pelo poder, que, aqui, dá-se na tensão pelo poder de (des)legitimação de discursos e práticas culturais de grupos sociais historicamente alijados da visibilidade e da valorização social.

\section{Experiências de campo: as festas de tecnobrega e reggae}

Aquilo que as festas actuais celebram não é a memória de marcas associadas colectivamente à totalidade dos domínios e das dimensões da experiência, mas marcas simbólicas de um domínio institucionalizado num campo social, num campo de forças que se impõe pela delimitação de um domínio específico da tensão com os restantes domínios da experiência.

RODRIGUES, 2005, p.15

Expressar marcas simbólicas nos espaços das festas de tecnobrega e de reggae é o que identifica e localiza politicamente os coletivos de jovens pobres de Belém - PA e São Luís - MA. Nas linhas a seguir, descrevo as duas primeiras experiências de campo relacionadas a esta investigação: a primeira em uma festa de tecnobrega da aparelhagem Badalasom - O Búfalo do Marajó - no Clube Social do Tuna Luso em Belém - PA, no dia 
18 de maio de 2012. A outra experiência aconteceu em uma estrutura montada ao lado do Largo de São Pedro, em uma grande festa de reggae da radiola Itamaraty, à véspera do dia de São Pedro, dia 28 de junho de 2012, maior festejo popular do Maranhão, no qual, anualmente, todos os grupos de bumba-meu-boi pedem benção ao santo padroeiro dos festejos juninos em São Luís - MA.

Na primeira experiência de campo, o NUPPI - Núcleo de Pesquisa e Produção de Imagem, através da minha pessoa e do bacharel em fotografia e técnico em fotografia do IFMA, Carlos Eduardo Cordeiro, foi convidado pelo fotógrafo maranhense Márcio Vasconcelos para representar o Maranhão no ENNEFOTO 2012 - Encontro Norte-Nordeste de Produtores Culturais em Fotografia, e apresentar um panorama da fotografia do Estado no evento. Este evento foi realizado em Belém - PA, na segunda metade do mês de maio de 2012, e organizado pela Fotoativa, organização voltada à produção e à difusão da fotografia no Estado do Pará. Liderado por Miguel Chicaoka, o evento discute as políticas públicas e sociais que se dão através da produção fotográfica. Nos coffee breaks, procurava saber com os colegas de Belém onde aconteceria alguma festa de tecnobrega, sem, no entanto, obter uma resposta precisa, apesar dos paraenses terem sido extremamente gentis, tentando, inclusive, perguntar a outros colegas se sabiam de alguma festa de tecnobrega que fosse acontecer.

No dia seguinte, logo cedo, comprei todos os jornais da cidade para tentar encontrar nas agendas culturais alguma notícia ou informe publicitário de festas de tecnobrega. Não achei nada. Fui à internet e busquei nos sites de eventos as programações das aparelhagens, só aí encontrei a festa da Badalasom - O Búfalo do Marajó na noite de sexta-feira, dia 18 de maio de 2012. Quando perguntei aos colegas de Belém - PA se era seguro ir ao baile de tecnobrega com equipamentos de filmagem e fotografia, a maioria (4 ou 5 pessoas) disse ser perigoso, mas duas pessoas disseram que não haveria problema algum. As festas de tecnobrega são eminentemente divulgadas através das rádios, não havendo, pelo que observei, espaço para o tecnobrega nas grandes mídias impressas.

Na noite do dia 18 de maio de 2012 fomos eu, Eduardo Cordeiro e o outro representante da delegação do Maranhão no ENNEFOTO 2012, José Reinaldo Martins (jornalista, mestre em comunicação e especialista em história da fotografia) para o clube Tuna Luso, por volta das 23h. José Reinaldo serviu 
como um guia para nós em Belém, pois conhece muito bem a cidade e as pessoas do lugar.

Pegamos carona com um colega do evento, chamado Guilherme, que nos deixou em frente ao clube. A festa estava ainda em seu início. Descemos com o equipamento, duas câmeras fotográficas, uma Nikon D9o e uma Nikon D300o, e uma câmera filmadora Panasonic HPX 170. Apresentei-me a um dos seguranças da porta do evento como coordenador de uma pesquisa sobre o tecnobrega, e pedi a ele que nos deixasse entrar para realizar imagens da festa. Ele perguntou quantas pessoas formavam a equipe e eu respondi três. Ele foi falar com algum tipo de coordenador da festa, que autorizou nossa entrada no recinto sem fazer maiores indagações.

Ao entrar na festa, percebi uma grande área aberta com várias barracas em volta do terreiro, sendo que, ao fundo, encontrava-se a atração principal da noite, a aparelhagem Badalasom. Ainda era cedo, e a festa estava apenas começando. O praticável do DJ, que em Belém se chama cabine, é impressionante: uma grande cabeça de búfalo estilizada em formato futurista, com uma armação de ferro fosco com olhos iluminados. Nas laterais, barracas de comida, de bebida e de gelo, com enormes quantidades em cada uma delas.

Os garçons circulavam pelo terreiro com mesa numa mão e um balde de gelo com várias cervejas em lata na outra, anunciando para o público presente o preço: a mesa era $\mathrm{R} \$$ 5,oo reais e o balde com 6 cervejas, $R \$ 12$,oo reais. Os dois são vendidos juntos. Não há cadeiras na festa, só há mesas para acomodar as cervejas, para que os grupos possam dançar e se divertir mais livremente.

À medida que o tempo passou, o público foi enchendo a festa, e o espaço foi tomado por grupos de jovens que se aglomeravam em volta da cabine do DJ Darlan, que agitou a galera. A dança que identifica a aparelhagem Badalasom - $\mathrm{O}$ Búfalo de Marajó - é o passo do "chifrinho", no qual os dançantes inclinam a cabeça para frente e colocam as mãos na cabeça imitando chifres de touro; então, balançam a cabeça tal como um touro. Os sujeitos vibram muito quando o DJ Rafael Cassiano profere: "Faz o chifrinho!!!" [Sic]. O set list do DJ é composto por músicas de tecnobrega, mas vez ou outra tocam outros ritmos, como forró e brega. Por volta de ih da manhã, a festa chegou ao seu ápice, tendo a área livre toda tomada pelo público presente. E, quanto mais cheio, mais o som frenético e a dança rápida contagiavam as pessoas, que ficavam cada vez mais empolgadas ao ritmo do tecnobrega. 
Mas o aspecto mais impressionante da festa de tecnobrega, sem dúvida, é a grandiloquência visual da aparelhagem, que, através de um enorme telão atrás do DJ, projeta imagens e frases que conduzem o evento. Também existe sistema de iluminação a laser, que lança luzes para todos os lados. Associado a isso, assoma-se a imagem da cabeça do búfalo gigante, que compõe a identidade visual da aparelhagem. É tudo muito grande e brilhante. Extasiante aos olhos.

Sonoramente, o tecnobrega é uma música aguda, e seus arranjos se dão muito em função de sintetizadores que produzem efeitos que vão do médio grave aos agudos e da batida acelerada do brega, em uma textura musical mais eletrônica do ritmo begine (que é o ritmo produzido pelos teclados eletrônico característico e fundante do gênero brega), com uma roupagem seca timbricamente.

Com relação aos jovens, observei que estavam em grupos, menores ou maiores, e compunham a grande maioria dos frequentadores da festa. A moda é muito interessante, na medida em que mescla um estilo interiorano de vaqueiro, pois muitos usam chapéus de boiadeiro e jeans, enquanto outros se vestem próximo ao estilo surf.

Muitos dos jovens ficam tirando fotos, com celulares e máquinas fotográficas, do grupo de que fazem parte durante a festa, enquanto também há uma dezena de fotógrafos homens e mulheres, circulando pela festa, fazendo fotos das pessoas ao preço de $\mathrm{R} \$ 15$,oo reais, fotos essas que são entregues na hora, com os dizeres, frases ou nome das pessoas, aquilo que as personagens da foto quiserem incluir nela. Por duas vezes, fui confundido com um fotógrafo da festa. Em uma dessas vezes, um vendedor ambulante chamado Carlos me pediu para fazer uma foto dele com o irmão, o Diogo, que estava aniversariando no dia. Fiz a foto deles dois com mais um amigo, mas quando eles souberam que eu não tinha como imprimir a foto na hora e colocar os dizeres do aniversariante, ficaram um pouco frustrados. No dia seguinte, enviei a foto para um e-mail que eles me deram. Nunca obtive retorno.

No procedimento de campo, resolvi que iniciaríamos fotografando e depois, quando a festa já estava mais cheia de gente, realizamos a filmagem. Percebi que, com as fotografias, consegui registrar a performance dos coletivos de jovens adeptos de tecnobrega em sua dinâmica mais "natural". Quando ligamos a câmera de filmar, as pessoas se projetaram para frente da câmera e "performaram" para ela. Talvez pela força do poder do audiovisual, talvez pela naturalidade da presença 
das câmeras fotográficas no ambiente. Nas imagens que se seguirão, apresento algumas fotografias que foram produzidas nessa ocasião.

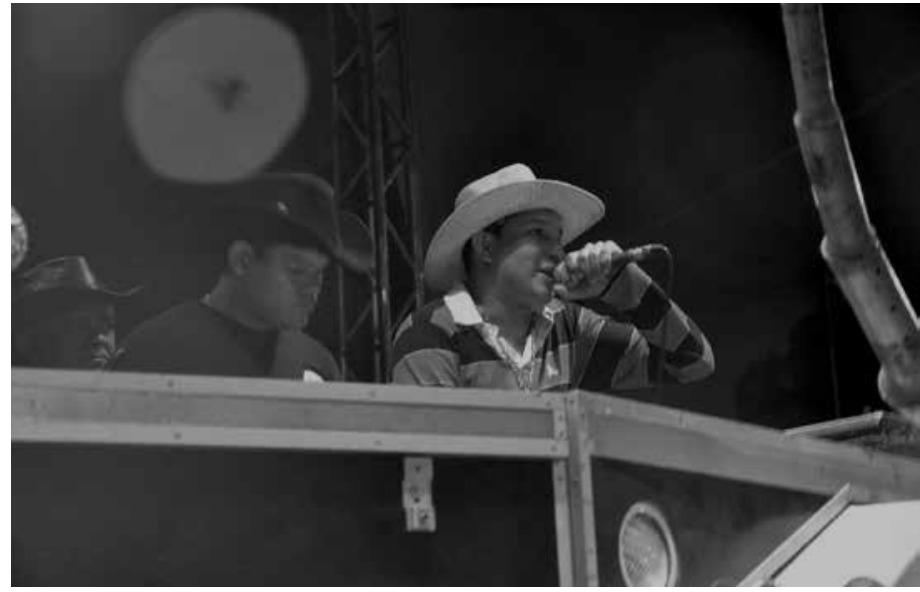

Figura 1: A interação do DJ Darlan.

\section{Figura 2: A imagem}

impressionante do praticável do Búfalo do Marajó.

Figura 3: O trabalho fundamental dos vendedores na cadeia produtiva.
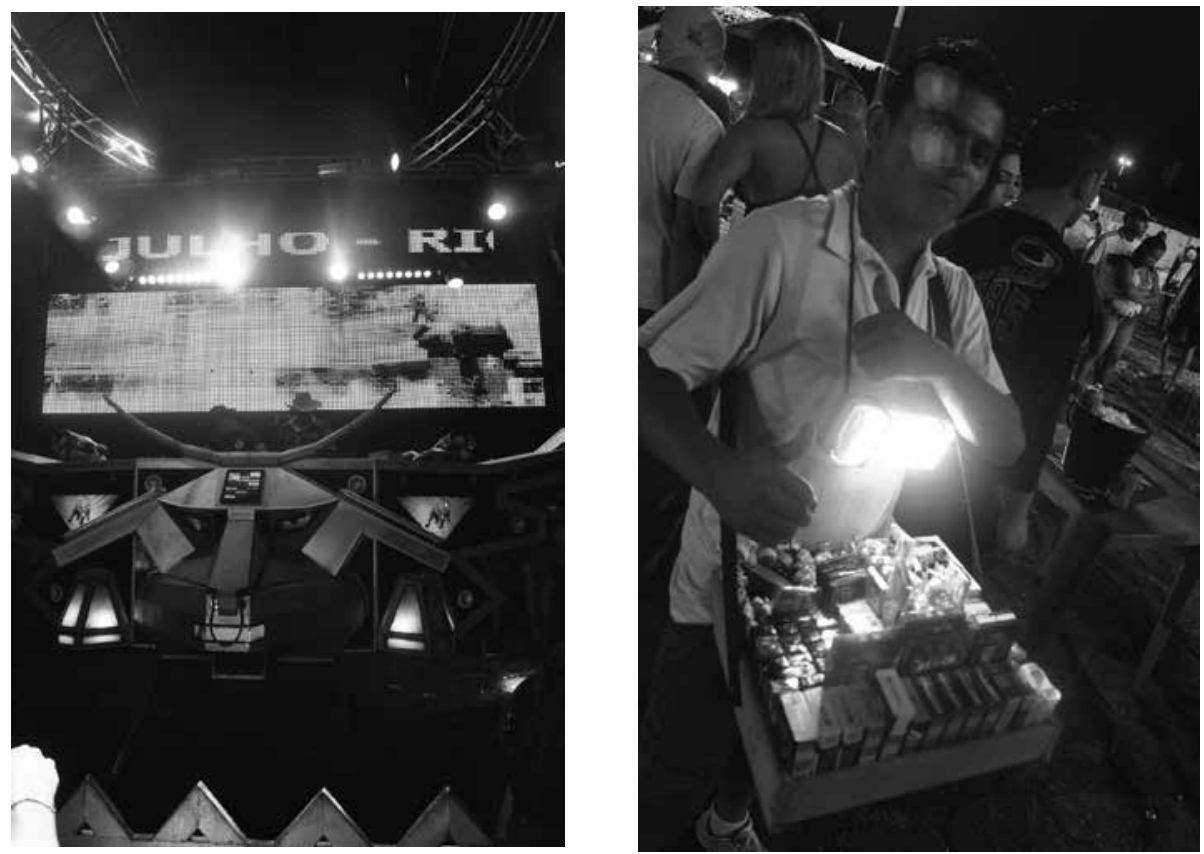

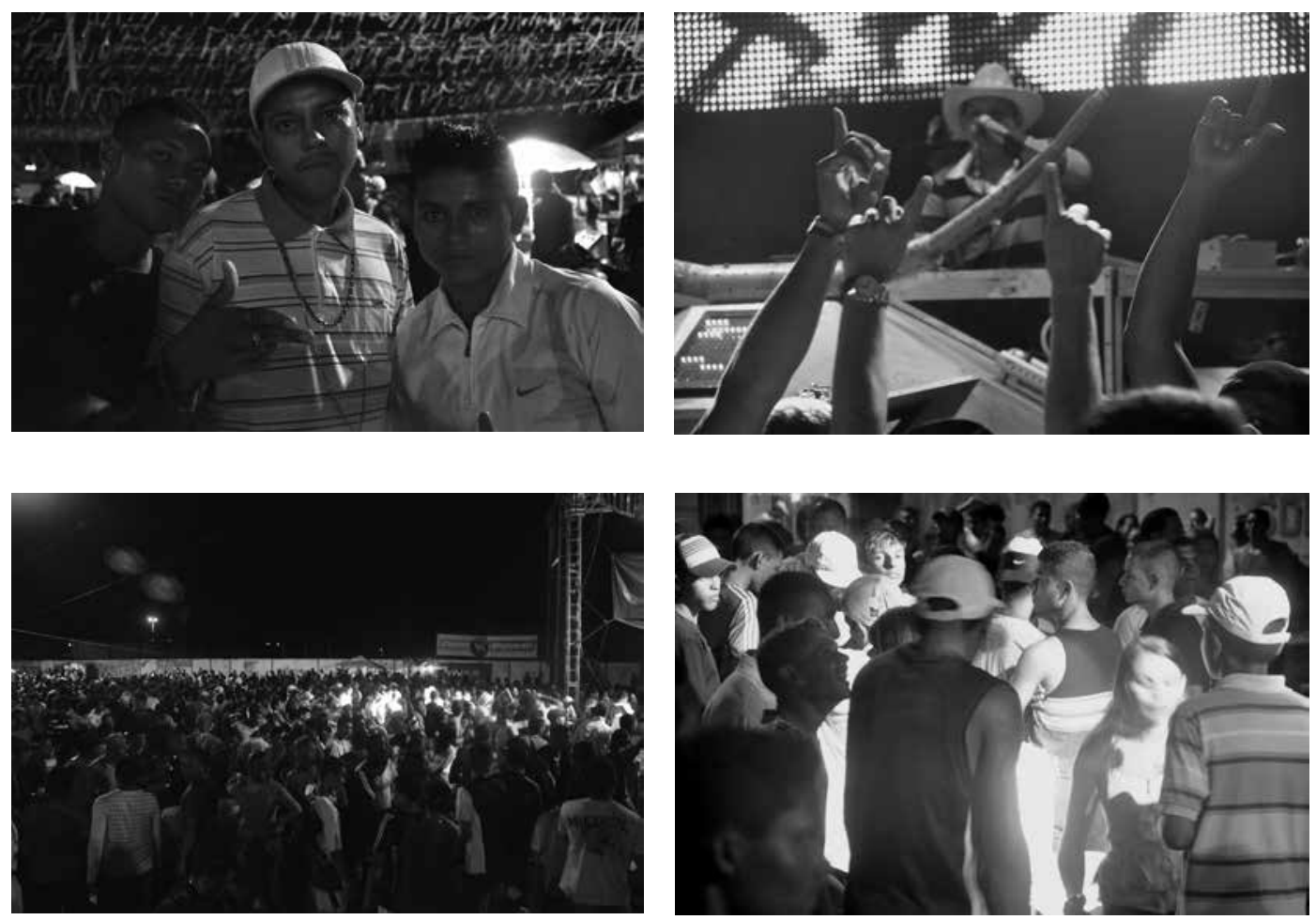

Figura 4: Foto do aniversariante

Diogo, que está ao centro, ao lado do irmão Carlos à direita e de um amigo, fazendo pose gangsta.

Figura 5: A reação do público à fala do DJ.

Figura 6: A massa no ápice de público da festa.

Figura 7: Som e luz como vetores do movimento e da performance.

Figura 8: Faz o chifrinho! Grito de guerra da aparelhagem Badalasom, o Búfalo do Marajó.

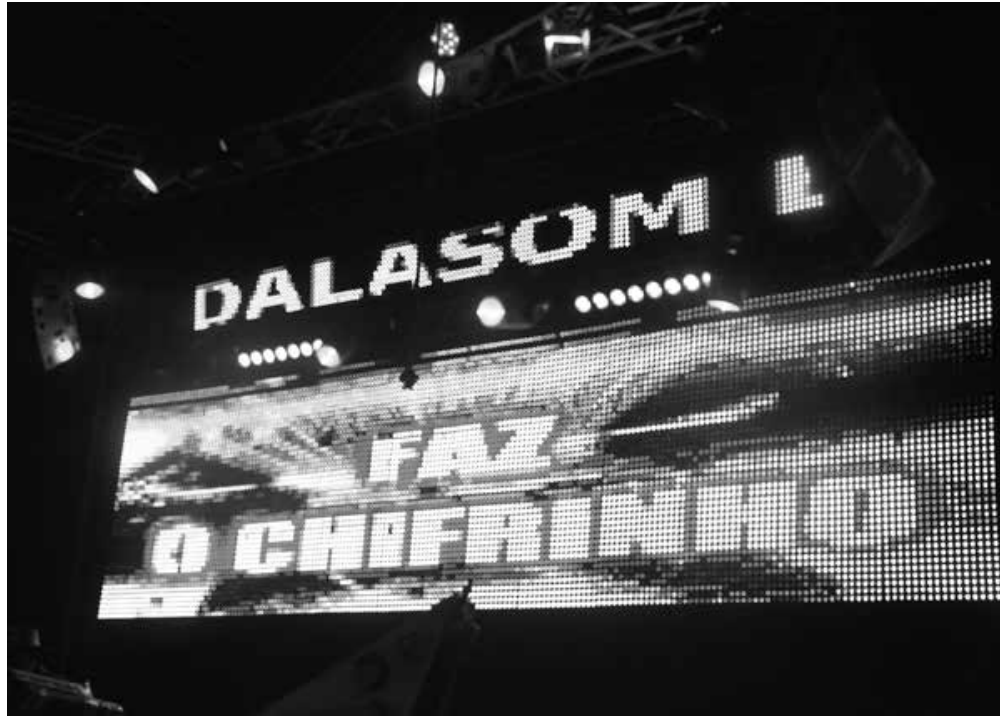




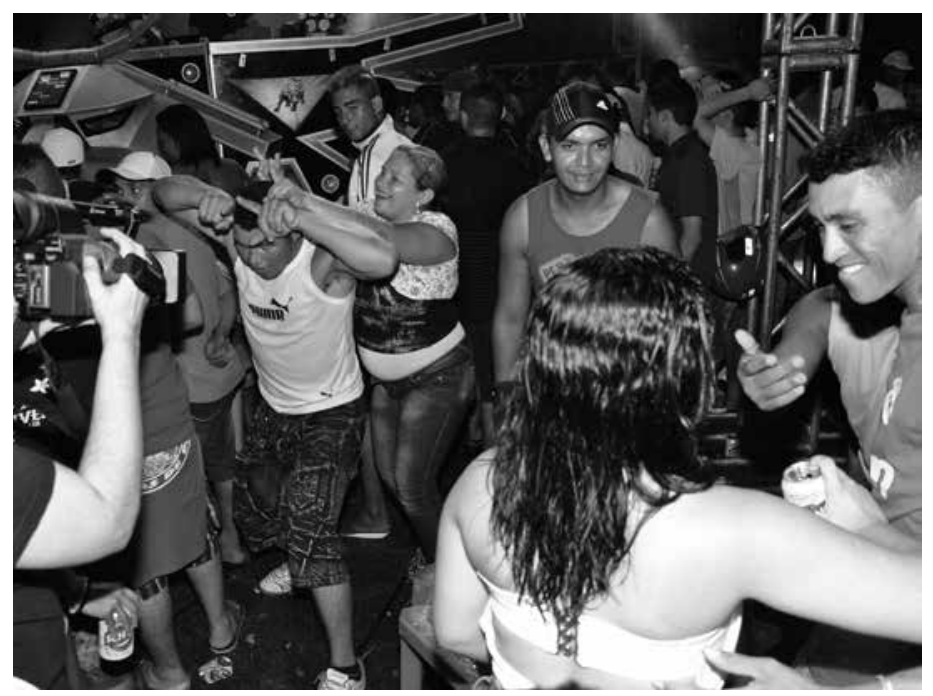

A segunda experiência de campo foi num baile de reggae da radiola Itamaraty, do deputado federal Pinto da Itamaraty, que está na sua segunda legislatura (2011 - 2014), levado ao Congresso Nacional pelo voto dos regueiros maranhenses. O baile aconteceu numa estrutura montada pela própria radiola nas proximidades do Largo de São Pedro, no dia 28 de junho de 2012, às vésperas do Dia de São Pedro, maior festa popular do Estado do Maranhão e da cidade de São Luís. No Maranhão, reggae e política institucional caminham lado a lado.

Nesse dia, a equipe de campo era composta por mim, pela fotógrafa e doutoranda em comunicação e cultura Carolina Guerra Libério, e pelo meu orientando de bolsa de iniciação científica (PIBIC Jr.), o aluno do $3^{\circ}$ ano do $2^{\circ}$ grau do curso médio técnico integrado em artes visuais do IFMA, Guilherme Lima Campos.

No reggae, diferentemente do tecnobrega, o ambiente é mais escuro, e não há um apelo visual tão forte quanto no tecnobrega. No reggae, prima-se mais pela potência do som, que é sentido fortemente através das vibrações das frequências graves nos corpos das pessoas presentes nos bailes. Observei uma mesma disposição circular dos elementos, com as caixas de som e as barracas de bebidas postas em volta do grande terreiro onde as pessoas dançam reggae.

Os grupos de jovens se localizam mais nas proximidades das caixas de som, para poderem sentir as vibrações corporais, porém, também existe um número de pessoas que vão para

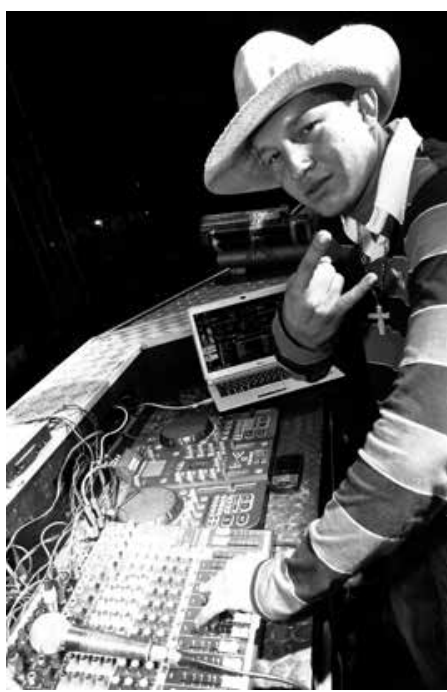

Figura 9: Bailante fazendo o chifrinho e performando para a minha câmera.

Figura 10: DJ da festa fazendo o sinal do chifre com a mão, marca gestual da aparelhagem. 
perto do DJ, só que bem menos do que no baile de tecnobrega. O praticável do DJ no reggae também é bem mais modesto do que no tecnobrega. Mas a figura do DJ no baile de reggae também é central. É ele que comanda a festa.

As pessoas dançam reggae no Maranhão em pares, aos moldes de um passo de bolero adaptado. Nessa ocasião, vimos vários casais bailando em estado de transe, ao utilizarem o espaço da festa para evoluírem seus passos. Muitos também bailam sozinhos, ao lado das caixas de som, numa ânsia pela sensação vibracional proporcionada pelas vibrações graves das potentes radiolas.

A moda é basicamente de surf. Inclusive constatei o patrocínio de uma loja de roupas de surf na festa, que expunha sua marca através de um enorme balão gigante na entrada do evento, a Marcelo Surf Wear. O jeans também é muito usado. Porém, também haviam pessoas vestidas das mais diferentes formas, mesmo porque, naquela noite, era noite de São Pedro, e o reggae disputava atenção com o ápice dos festejos juninos em São Luís.

No reggae, senti as pessoas mais arredias às lentes das câmeras do que no tecnobrega. No entanto, não houve resistência às filmagens e às fotografias. Assim como em Belém, apresentei-me como coordenador de uma pesquisa sobre reggae e rapidamente nos autorizaram, a mim e a minha equipe, a entrar e a realizar registros de imagem no local. Este tinha uma segurança reforçada e estava extremamente lotado de gente, o que criava um ambiente propício ao registro. Realizamos imagens das pessoas dançando, dos grupos, dos capacetes dispostos em vários lugares da festa, tendo em vista que a maioria dos frequentadores dos bailes é da classe $C$, e possui como meio de locomoção uma moto popular. Outra grande parte tem na moto um meio de ganhar a vida, como os mototaxistas e os motoboys, classe de trabalhadores autônomos bem presentes nas festas de reggae.

A cada música tocada, o DJ vai proferindo frases que vão causando reações no público, que grita e se agita a cada nova "pedra", como é chamada a "boa" canção de reggae. Os grupos de jovens se colocam como protagonistas da festa quando esta alcança seu ápice, por volta de 1hзomin da manhã. Os casais e os grupos de jovens dançam avidamente para mostrar quem é o mais sagaz na hora de expressar o sentido do reggae através de movimentos corpóreos. Há, nesse momento, um evidente transe coletivo embalado a reggae e regado à bebida. O transe coletivo que posiciona étnica e politicamente esse 
corpo no espaço-tempo do vivido, através do movimento do corpo e do espaço de realização da festa. No tecnobrega, essa característica também é percebida, só que mais exacerbada corporalmente devido à velocidade da música e à iluminação do lugar, e menos transeúnica, tal como no reggae, que é mais cadenciado e lento.

Mas, o que mais interessa compreender é como que as músicas de tecnobrega e de reggae se constituem em reconstruções mestiças dos sons tradicionais vindos do Caribe, associados aos elementos tecnológicos dos sound systems e da música eletrônica. Os terreiros de realização das festas se apresentam tal como terreiros dos festejos populares, só que em proporções muito maiores. Nesse sentido, as festas remontam universos simbólicos residuais dos grupos étnicos mestiços (negros e indígenas) do meio-norte do Brasil, e geram campos de significações próprios e específicos que negociam o pós-moderno com o tradicional, conformando, assim, os gêneros/estilos musicais mais importantes e representantes dos coletivos de jovens menos abastados das cidades de Belém e São Luís. Esses posicionamentos identitários, essas políticas de representação se apresentam muito mais como uma resistência numa perspectiva de marcação de uma diferença ao hegemônico, do que propriamente um discurso opositivo ao hegemônico em relação à política-vida dos coletivos aqui observados. A seguir, apresentarei imagens fotográficas produzidas pela equipe em campo na festa radiola Itamaraty.
Figura 11: A vibe coletiva dos regueiros próximos a caixas de som na festa de reggae.

Os corpos se retroalimentam na energia da dança, do som e do "estar juntos".

Figura 12: Grupo de jovens dançando ao lado das caixas de som, que propiciam uma vibração descomunal do corpo sob a influência da potência sonora da música.
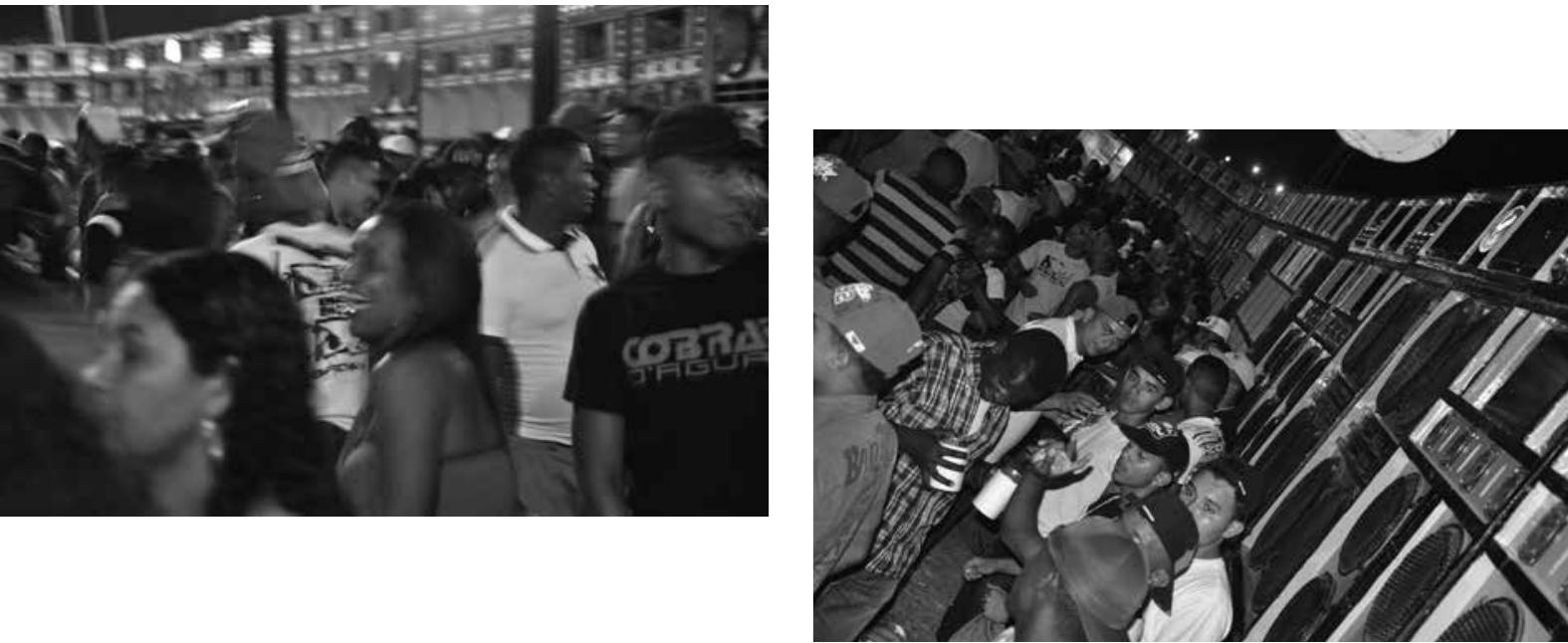

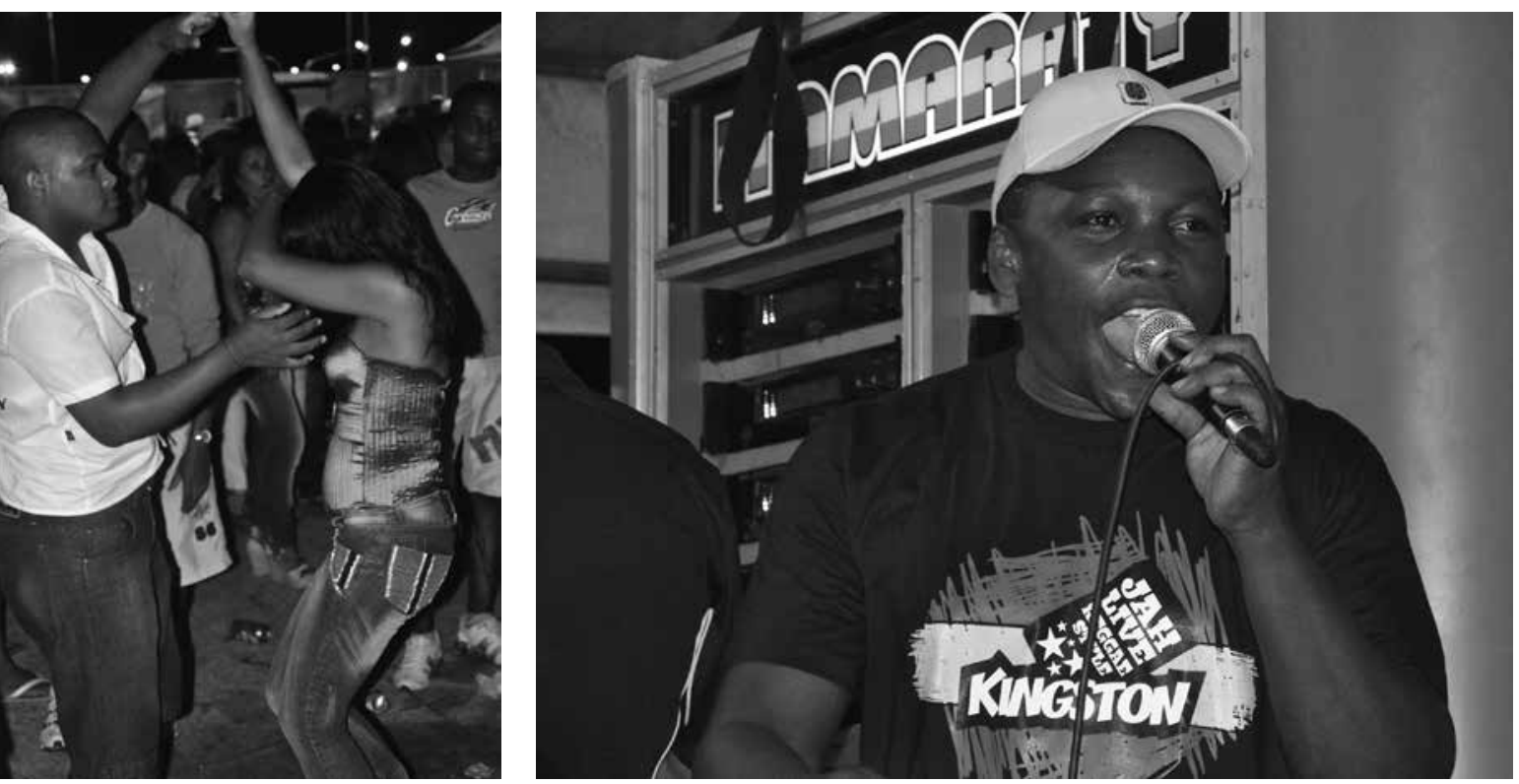

Figura 13: O bailado sincronizado do casal no rodopio da dançarina.

Figura 14: DJ Junior Black "agitando" a massa regueira.

Figuras 15 e 16: Regueiro dominando o espaço na dança em performance de salão.
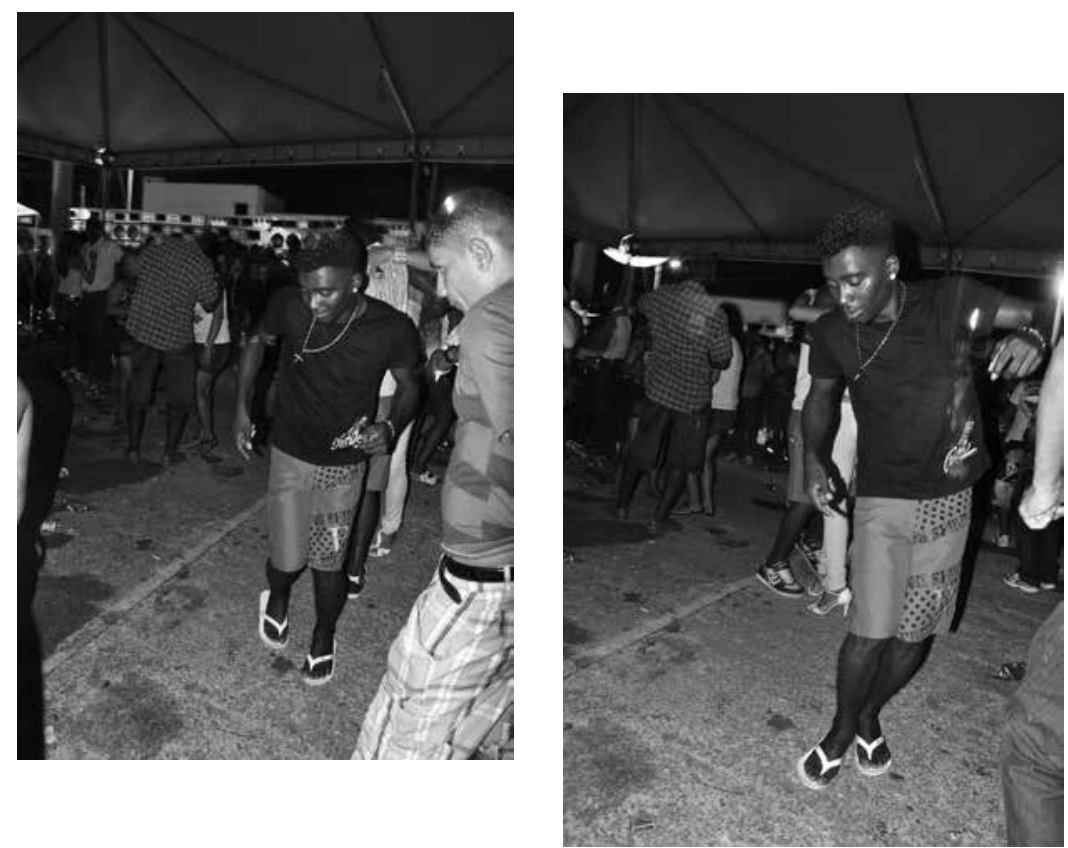


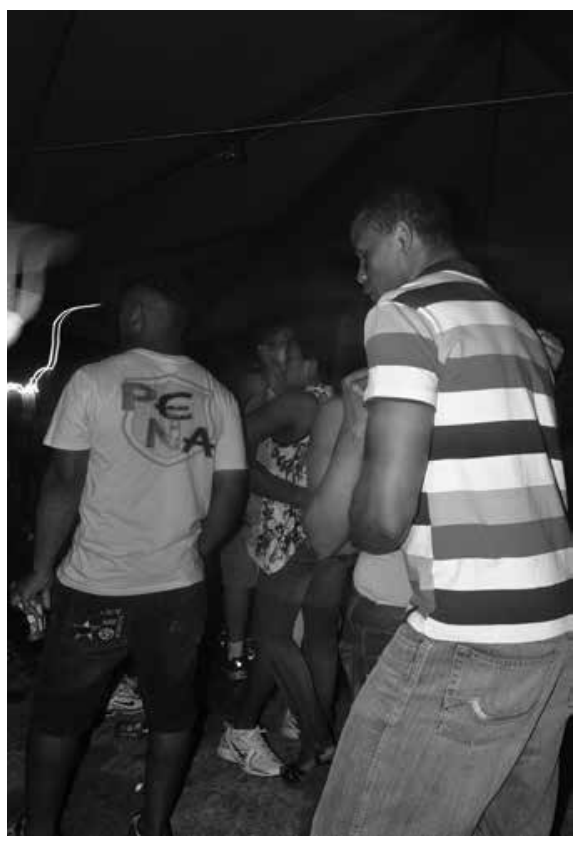

Figura 17

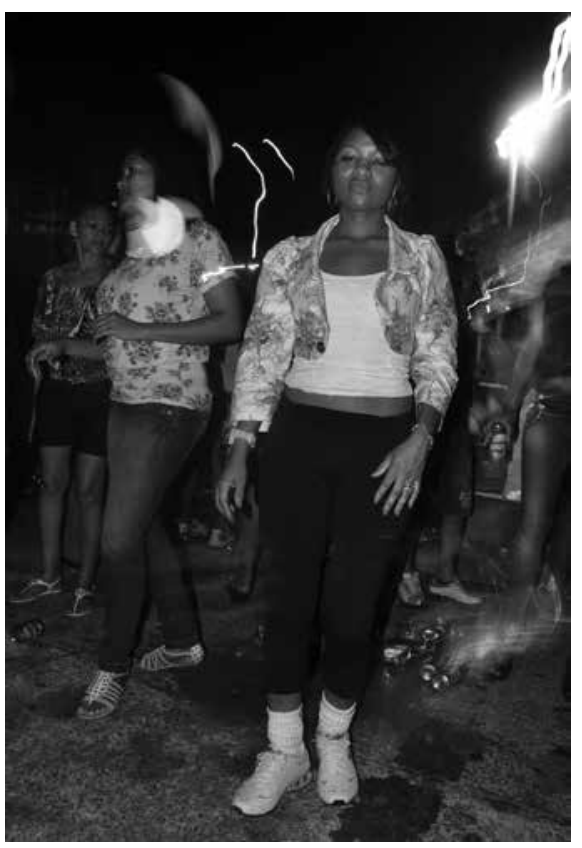

Figura 18: "O estilo" 

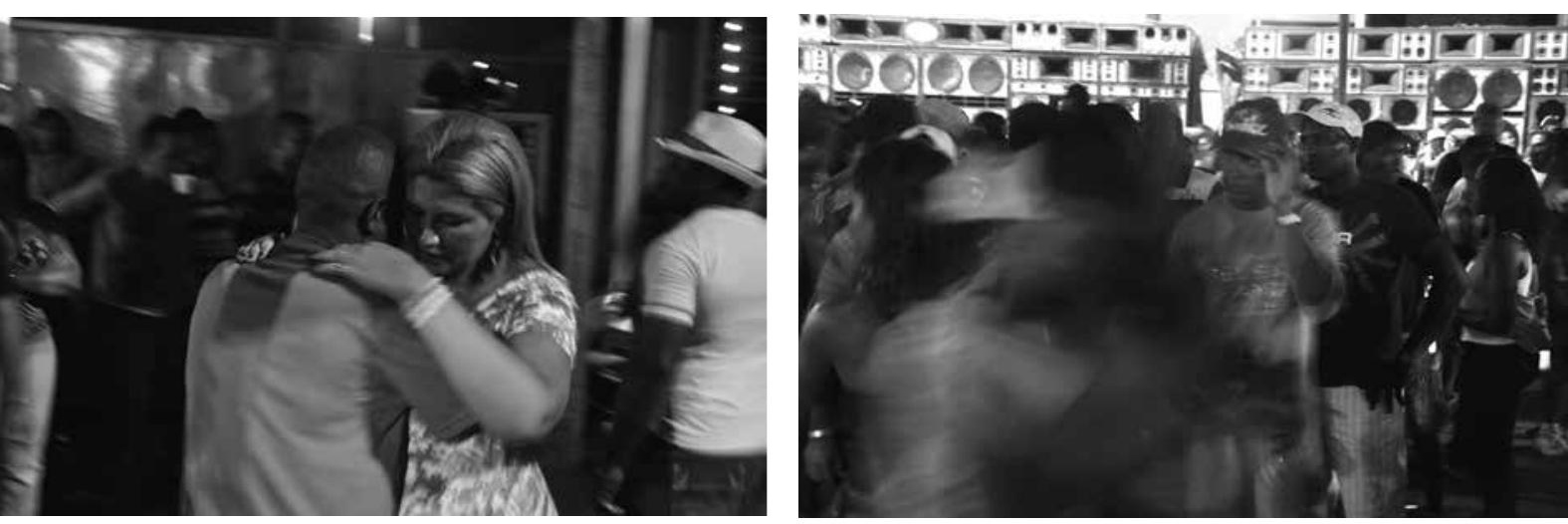

Figuras 19 e 20: "O charme"

O que propus aqui apresentar foi um pequeno esboço de documentos fotográficos das festas de tecnobrega e reggae, em Belém - PA e São Luís - MA, respectivamente, que intentaram desvelar, na medida do que as lentes fotográficas são capazes de captar, os traços e o engajamento dos corpos que estão comprometidos com o movimento da cultura.

Curiosamente, a fotografia só pode registrar o movimento desses corpos em sua paralização. E é aí que está o verdadeiro poder dialético da fotografia: registrar o movimento na sua imobilidade. Tal como descreve o filósofo italiano Domenico de Piacenza, em meados do séc. XV, no seu texto De la arte di ballare et danzare [Sobre a arte de bailar e dançar]:

Digo a ti, que quer aprender o ofício, é necessário dançar por fantasmata, e nota que fantasmata é uma destreza corporal, que é movida com o entendimento da medida [...] parando de vez em quando como se tivesse visto a cabeça da medusa, como diz o poeta, isto é, uma vez feito o movimento, sê de todo pedra naquele instante (...) (Apud AGAMBEN, 2012, p. 23-24).

Nós, fotógrafos, proporcionamos, com a nossa imagem técnica, uma fantasmata das coisas que se dão na fruição temporal dos acontecimentos, proporcionando que alguns momentos sejam "todo pedra naquele instante". Essa imobilidade possibilita a contemplação e a reflexividade necessárias para se observar/pensar sobre os signos e os significados das manifestações das culturas populares urbanas. 


\section{Algumas considerações}

As imagens revelam dimensões dos fenômenos culturais não descritíveis pelos métodos tradicionais de investigação de campo. $\mathrm{O}$ intuito dessa pesquisa não é usar exclusivamente a antropologia visual como método de campo, mas atentar que, para desvelar os signos do corpo, os dispositivos de captura e registro de imagens são fundamentais ao êxito desse intuito. Outra questão que me interessa particularmente é a necessidade de descentralizar a produção de conhecimento do texto verbal escrito, e procurar assomar aos caminhos clássicos da experiência do conhecimento, novas linguagens e miradas na busca por alargar as fronteiras da comunicação, através do contato com outras áreas, como os estudos de performance, as artes visuais e as ciências sociais, por exemplo.

O presente texto é o esforço de dispor os referenciais metodológicos que guiam esse trabalho, sobretudo na sua tentativa de abstrair do corpo seus significantes simbólicos de resistência e identidade. Portanto, por estar em movimento, o objeto está sempre a se (re)construir metodologicamente em campo. Neste sentindo, apresenta muito mais considerações transitórias e historicamente situadas que conclusões em si.

Por fim, quero frisar que uma das principais questões a ser observada nessa trajetória de pesquisa é identificar que o sentido da resistência dos grupos estudados se localiza num sentimento de diferença ao hegemônico, numa distinção ao "gosto" socialmente "desejado", como uma questão de posicionamento político e identitário, como estratégia de resistência simbólica, como opção para um outro discurso possível, como condição social propícia para a construção de um "nós" em posição relacional a um "eles". As políticas e performances de representação desses grupos frente às lentes da equipe de campo são respostas corporais, gestos discursivos ressignificantes das visibilidades violentas e, muitas vezes, desqualificantes, estabelecidas pela maioria das mídias de massa, pelos setores conservadores das classes mais abastadas e pelos aparelhos de controle do Estado aos gêneros/ estilos do reggae e do tecnobrega e seus públicos no Brasil.

\section{Referências}

AGAMBEN, Giorgio. Ninfas. São Paulo: Hedra, 2012.

ALABARCES, Pablo A.; RODRÍGUEZ, María G. (Comps.). Resistencias y mediaciones. Estudios sobre cultura popular. Buenos Aires: Paidos, 2008 
ARAÚJO, Elaine Peixoto. O reggae ludovicense: uma leitura do seu sistema léxico-semântico. Revista Philologus: Círculo Fluminense de Estudos Filológicos e Lingüísticos. Ano 10, Número 28, Rio de Janeiro: CiFEFil, 2004.

BENJAMIN, Walter. Passagens. Belo Horizonte: UFMG; São Paulo: Imprensa Oficial, 2009.

BRASIL, Marcus Ramúsyo de A. O reggae no Maranhão: música, mídia, poder. 2011, 217 f. Tese (Doutorado em Ciências Sociais / Política). Programa de Estudos Pós-Graduados em Ciências Sociais, Pontifícia Universidade Católica de São Paulo.

. São Luís, a Jamaica brasileira: o reggae dos toca-discos à produção midiática. 2005, $100 \mathrm{f}$. Dissertação (Mestrado em Comunicação). Programa de Pós-Graduação em Comunicação, Universidade Paulista.

BUENO, Francisco da Silveira. Novo dicionário escolar da língua portuguesa. São Paulo: Edições Fortaleza, 1972.

CUNHA, Antônio Geraldo da. Dicionário etimológico da língua portuguesa. Rio de Janeiro: Lexicon Editora Digital, 2007.

HEBDIGE, Dick. Cut'n mix. New York: Comedia, 1987.

LEMOS, Ronaldo e CASTRO Oona. Tecnobrega: o Pará reinventando o negócio da música. Rio de Janeiro: Aeroplano, 2008.

NOVAES, Sylvia C. O uso da imagem na antropologia. SAMAIN, Etienne (org.). O fotográfico. São Paulo: Senac, 2005. RODRIGUES, Adriano Duarte. A festa, hoje. In: Revista Cambiassu - Estudos em comunicação. Vol. 15, № 1. São Luís: EDUFMA, 2005. p. 7-18.

SILVA, Carlos Benedito Rodrigues da. Da terra das primaveras à ilha do amor: reggae, lazer e identidade cultural. 1992. Dissertação (Mestrado em Antropologia). Programa de Pós-Graduação em Antropologia Social, Universidade Estadual de Campinas.

SODRÉ, Muniz. Samba, o dono do corpo. Rio de Janeiro: Mauad, 1998.

WILLIAMS, Raymond. Marxismo y literatura. Barcelona: Ediciones Península, 1997.

ZUMTHOR, Paul. Performance, recepção, leitura. São Paulo: Cosac Naify, 2007.

\section{NOTAS}

1. As radiolas são as versões maranhenses dos sound systems jamaicanos. Empresas com toda estrutura de som e palco, com caixas de som coloridas formando verdadeiros paredões com uma potência sonora enorme e com 
grande poder de afetação vibracional sobre os corpos do público presente. Os empresários donos das maiores radiolas de reggae do Maranhão são conhecidos como magnatas, em sinal de status social e riqueza econômica, tendo em vista o grande mercado que conforma as festas de reggae em São Luís e em algumas cidades do interior do Maranhão.

2. Poético no sentido primeiro da poesia que é: "Aquilo que desperta o sentimento do belo" (CUNHA, 2007, p. 617). E, que, também se instaura enquanto aquilo que é em “... sua essência, pois, o ritmo" (BUENO, 1972, p. 899).

3. A religião rastafári representa uma reação de origem local contra os padrões de espiritualidade impostos pelas religiões advindas da Europa. $\mathrm{O}$ movimento surgiu na Jamaica entre a classe trabalhadora e os camponeses negros, em meados dos anos 1930.

4. Este termo cognominava os burru men, pessoas consideradas párias da sociedade. Habitantes da zona rural que cultuavam entidades africanas e tocavam os tambores tribais chamados burru drums, o ritmo nyiabing.

Recebido em: 07/10/13

Aceito em: 08/11/13

\section{MARCUS RAMUSYO DE ALMEIDA BRASIL}

ramusyo@hotmail.com

Pós-doutorando em Comunicação e Cultura (UFRJ). Pós-Doutor em Ciencias Sociales, Niñez y Juventud (CLACSO). Doutor em Ciências Sociais (PUC-SP). Mestre em Comunicação. Professor do IFMA na área: Comunicação / Fotografia e Multimídia. Coordenador do NUPPI (IFMA) - Núcleo de Pesquisa e Produção de Imagem. Pesquisador do NEAMP (PUC-SP) - Núcleo de Estudos em Arte, Mídia e Política. 